\title{
JOURNAL.RU
}

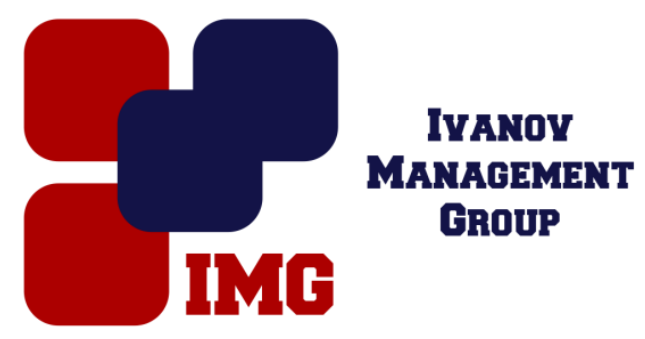

Разбаков И.О.

Чуватский государственный университет имени И.Н. Ульянова Чебоксары, Россия

doi: 10.18411/lj-30-06-2017-24

idsp 000001:1j-30-06-2017-24

\section{Методы оценки инвестиционного проекта}

\section{Аннотация}

Статья посвящена анализу основных методов оценки инвестиционных проектов, выявлению их преимуществ и недостатков.

Ключевые слова: метод оценки инвестиционного проекта, уровень рентабельности, срок окупаемости, эффективность инвестиционного проекта.

Анализ финансово-экономической литературы по вопросам оценки инвестиционного показал, что мнения, о том какие из методов оценки наиболее эффективны и точнее, расходятся. Сложность выбора метода оценки связана с разными основными показателями при расчетах, в зависимости от типа проекта. Например, на внутреннюю ставку прибыли финансируемых проектов влияют отрасль экономики, принадлежность предприятия (государственная или частная), степень риска. Например, инвесторы в горнорудный проект могут затребовать более высокой ставки дохода для возмещения большего риска, которому они подвергаются по сравнению с инвесторами в аграрное предприятие. Так же существует зависимость от интересов инвестора. Частные инвесторы, чаще заинтересованы только в своих интересах при выборе проекта для инвестирования и требуют уровень больше нормы прибыли, чем государство, осуществляющее общественные задачи. Так же многообразие подходов в оценке инвестиционных проектов связано с небольшими отличиями в итоговых показателях. У всех методов есть свои преимущества и недостатки. Этим объясняется их разнообразие. Но все же существуют наиболее популярные 
способы, которые зарекомендовали себя уже практикой их применения. Для легкости освоения методов оценки и для простоты формирования представления об этом, данная статья будет посвящена основным и наиболее зарекомендовавшим себя в практике их применения.

Итак, основная проблематика оценки привлекательности инвестиционного проекта состоит в определении уровня его рентабельности. В отечественной практике инвестиционного проектирования методы оценки эффективности инвестиций делятся на две группы: методы дисконтирования; статические или простые.

Многие авторы относят к простому методу оценки расчет срока окупаемости. Расчеты при использовании этого метода достаточно простые, что является его основным достоинством. Суть его заключается в определении срока возмещения изначального вклада из чистых поступлений, то есть определяется срок, за который поступления от деятельности предприятия возместят затраты на инвестиции. В тех случаях когда ежегодные финансовые зачисления различны, то расчет производится планомерно, при этом на каждом промежутке планирования из общего объема изначальных затрат вычитаются чистая прибыль и амортизационные отчисления (пока не станет отрицательным). Недостаток этого метода в выборе срока окупаемости, он может быть субъективен. Данный метод не может применяться при сравнении различных вариантов с различными сроками жизни, но одинаковыми периодами окупаемости, так как не учитывает прибыльность проекта за сроки окупаемости. Срок окупаемости - это, прежде всего, ограничение, но не основной критерий выбора. Проект исключается из списка возможных инвестиционных, если период окупаемости проекта больше, чем принятое ограничение. Такой метод будет удобен для быстрого оценивания проектов в условиях нехватки ресурсов.

Предлагаю к рассмотрению следующий простой способ оценки - простая норма прибыли. Данный способ показывает, какая часть инвестиционных расходов компенсируется в виде прибыли в течение одного периода планирования. Сравнивая прогнозируемую величину нормы прибыли со средним или минимальным уровнем рентабельности, инвестор может сделать вывод о целесообразности следующего анализа этого инвестиционного проекта.

$$
\text { SimpleRateOfreturn }=\frac{\text { чистаяприбыль }}{\text { инвестиционныезатратьл }}
$$

Как и в первом методе, преимуществом является простота расчетов. Помимо этого, оценивается прибыль проекта. Недостаток - не учитывается 
прибыльность будущих зачислений, основная зависимость от чистой прибыли выбранной величины.

Понимание и учет факта неравнозначности одинаковых платежей или сумм поступлений, относящихся к разным временным промежуткам очень важно для правильной оценки проектов, связанных с длительным вложением капитала.

К наиболее используемым методам дисконтирования относятся следующие:

Чистая текущая стоимость (net present value) NPV

Индекс прибыльности (Profitability index) PI

Отношение выгод к затратам (benefit/cost ratio) B/C ratio

Внутренняя норма доходности или прибыльность проекта (internal rate of return) IRR

Период окупаемости (payback period)

Рассмотрим более подробно некоторые из них.

При оценке инвестиционного проекта методом чистой текущей стоимости, учитывается эффективность инвестиционного проекта, который рассчитывается путём дисконтирования ожидаемых денежных потоков (доходов и расходов). Рассчитывается текущая стоимость будущих денежных поступлений от проекта, текущая стоимость затрат, для чего доходы приводятся к текущей дате (за каждый год). Данный метод можно представить несколькими формулами, наиболее часто употребляемыми в финансовом анализе.

ЧТСД (чистая текущая стоимость доходов) = ПД - ПР,

где ПД - суммарные приведенные доходы,

ПР - приведенные затраты по проекту;

или (более подробно):

$$
N P V=\sum_{i=1}^{n} \frac{D_{i}-K_{i}}{(1+d)^{i-1}},
$$

где Di - доходы i-го периода,

Ki-затраты і-го периода,

n- количество периодов реализации проекта,

d - норма дисконта.

или тождественная ей

$$
N P V=\sum_{t=0}^{n} \frac{C F_{t}}{(1+k)^{t}},
$$


где $\mathrm{CFt}$ - чистый денежный поток t-го года,

k - средневзвешенная стоимость капитала (WACC).

При выборе инвестиций, когда учитывается влияние инфляционных процессов, применяется универсальная формула NPV. Формула позволяет одновременно производить и инфляционную корректировку и дисконтирование.

$$
N P V=\sum_{t=1}^{n} \frac{\left[R_{t} \prod_{r=1}^{t}\left(1+i_{r}\right)-C_{t} \prod_{r=1}^{t}\left(1+i_{r}^{\prime}\right)\right] \cdot(1-T)+D_{t} T}{(1+k)^{t}}-I_{0},
$$

где $\mathrm{Rt}$ - номинальная выручка t-го года, оцененная для безинфляционной ситуации, т.е. в ценах базового периода,

ir - темпы инфляции доходов r-го года,

$\mathrm{Ct}$ - номинальные денежные затраты t-го года в ценах базового периода,

i'r - темпы инфляции издержек r-го года,

Т - ставка налогообложения прибыли,

I0 - первоначальные затраты на приобретение основных средств,

$\mathrm{k}$ - средневзвешенная стоимость капитала, включающая инфляционную премию,

Dt - амортизационные отчисления t-го года.

Метод ориентирован на достижение увеличения прибыли акционеров.

Размер чистой текущей стоимости не является полностью верным методом при выборе между проектами с различными первоначальными издержками и периодом окупаемости, что не дает судить о запасе финансовой прочности проекта и о пороге прибыльности.

Итак, при всех плюсах этот метод не дает сравнивать проекты с разной капиталоемкостью, но одинаковой NPV. B таких ситуация можно применять следующий метод: Индекс прибыльности. Ставка доходности проекта рассчитывается двумя способами:

$$
P I=\frac{N P V}{\sum_{i=1}^{n} \frac{K_{i}}{(1+d)^{i-1}}} \times 100 \% \quad \text { или } \quad \frac{\sum_{i=1}^{n} \frac{D_{i}}{(1+d)^{i-1}}}{\sum_{i=1}^{n} \frac{K_{i}}{(1+d)^{i-1}}}
$$

В первом случае коэффициент показывает уровень чистого приведенного дохода на единицу затрат. Во втором случае показатель является индексом, отражающим соотношение отрицательных и положительных финансовых потоков по проекту. Ставка доходности проекта отражает величину роста активов от реализации проекта на единицу инвестиций. 
Преимущества этого показателя в том, что он отражает эффективность единицы инвестиций и является относительным. Этот показатель дает возможность сформировать более эффективный инвестиционный портфель, при обстоятельствах ограниченности ресурсов.

Главный недостаток - это зависимость результатов расчета от ставки дисконта.

Внутренняя норма рентабельности. Внутренняя норма доходности (IRR) представляет собой ту норму дисконта (IRRBн), при которой эффект от инвестиций (NPV) равен нулю. Иными словами IRRBн является решением уравнения $(\mathrm{X})$ :

$$
N P V=\sum_{i=1}^{n} \frac{D_{i}-K_{i}}{(1+X)^{i-1}}=0
$$

Все затраты и поступления по проекту приводятся к настоящей стоимости на основе внутренней ставки рентабельности самого проекта, а не на основе задаваемой извне средней стоимости капитала. Внутренняя ставка рентабельности устанавливается как ставка доходности, при которой настоящая стоимость поступлений равна настоящей стоимости затрат (чистая настоящая стоимость проекта равна нулю - все затраты окупаются).

Расчет IRR может проходить по следующему алгоритму:

1. На основе произвольной ставки дисконтирования, высчитывается суммарная текущая стоимость доходов по проекту.

2. Расходы по проекту сравниваются с полученной приведенной суммой доходов.

3. Выбирается вторая ставка дисконтирования, если первоначальная произвольная ставка дисконтирования не дает нулевой чистой текущей стоимости доходов, по такому правилу: новая ставка дисконтирования должна быть больше первоначальной, если NPV > O; новая ставка дисконтирования должна быть меньше первоначальной , если NPV $<$ O.

4. Вторая ставка дисконтирования подбирается до тех пор, пока не получится суммарная текущая стоимость доходов как больше, так и меньше затрат по проекту.

5. Рассчитывается внутренняя ставка доходности проекта методом интерполяции в три этапа: а) определяется интервал между максимальной (ПДатах) и минимальной (ПДамin) величиной суммарных приведенных доходов и соответствующими им ставками дисконтирования (ст.д.max и ст.д.min);

б) составляется пропорция и решается уравнение 
$($ ПДах - 3П) / (ПДmax - ПДmin $)=($ ст.д.max - (ст.д.max + X)) / (ст.д.max ст.д.min)

$\mathrm{X}=$ ?,

где $3 П$ - затраты по проекту.

в) рассчитывается IRR = ст.д. $\max +\mathrm{X}$.

Метод хорошо согласуется с главной целью финансового менеджмента и сам по себе достаточно прост для понимания. В то же время метод предполагает сложные расчеты. Не всегда выбирается самый рентабельный проект. Метод предполагает не совсем реалистичную ситуацию реинвестирования всех промежуточных поступлений от проекта по ставке внутренней доходности. В реальности часть средств может быть инвестирована в надежные, но низкодоходные активы, такие, как краткосрочные государственные облигации, часть - выплачена в виде дивидендов. IRR сложно использовать для оценки инвестиционного портфеля в целом, так как он в отличие от показателя NPV характеризует только конкретный проект и не суммируется. IRR требует особого использования при изучении проектов, имеющих несколько больших отрицательных финансовых потоков в течение экономического существования проекта.

Таким образом, каждый из способов анализа инвестиционных проектов дает финансовому аналитику возможность изучить какие-то свои характеристики проекта, высветить важные подробности и детали, поэтому к анализу каждого из проектов опытные специалисты применяют все основные методы.

***

1. Дворцин М.Д., Голованов Е.В., Филиппов В.С., Юсим В.Н. Технологические основы развития экономики: Учебное пособие - М.: Издательство Рос. Экон. акад., 2011. - 65с.

2. Хазанович Э.С. Иностранные инвестиции.- М.: КноРус, 2011.

3. Бердникова Т.Б. Рынок ценных бумаг - М.: Инфра-М, 2004. -278 с . - (серия «вопрос ответ»). 